\title{
Cría cuervos e Todo sobre mi madre: família, cinema e subversão
}

SANDRA FISCHER Universidade Tuiuti do Paraná/UTP 


\section{Resumo}

Este artigo apresenta parte do estudo que estamos desenvolvendo a respeito do cinema espanhol, concentradamente no âmbito das películas que tratam da temática da família. Amparados na noção de que existe uma poética da família presente na obra dos principais cineastas espanhóis, apresentamos uma leitura de Cría cuervos, de Carlos Saura, e de Todo sobre mi madre, de Pedro Almodóvar, filmes representativos dessa tendência.

\section{Palavras-chave}

cinema, família, poética, Cría cuervos, Todo sobre mi madre

\section{Abstract}

This article presents part of the studies we have been developing about Spanish cinema, focusing on the representation of the family. Based upon the notion that there is a poetics of the family which permeates the work of the most important Spanish directors, we present an analyses of Cría cuervos and Todo sobre mi madre, both representative of this tendency.

\section{Key words}

cinema, family, poetics, Cría cuervos, Todo sobre mi madre 


\section{Do cinema e da família}

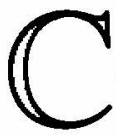

inema tem a ver com recorte e enquadramento, com encenação e montagem. Familia seria recorte, enquadramento, encenação e montagem? Em termos, sim. Termos genericamente colocados, evidentemente: não há dúvida de que tanto a economia do cinema quanto a da família vão muito além disso, sabemos todos - e como sabemos, principalmente no que se refere à noção de família. Porque se é certo que nem todo mundo é familiarizado com a multiplicidade de aspectos técnicos, materiais, poéticos, culturais, financeiros e outros tantos que envolvem a produção cinematográfica, é também certo que, marcando a vida de cada um, há sempre uma presença ou uma ausência de família. Seja como for, quando iniciamos nossos estudos sobre a questão da representação da família no cinema - a princípio, no âmbito do cinema espanhol - nos vimos caminhando pelas veredas da reflexão sobre o que seja e o que esteja implicado na idéia de recorte e enquadramento, encenação e montagem.

Essa correlação um tanto extravagante, de um certo ponto de vista, nos pareceu instigante e conveniente, não apenas porque fez algum sentido em termos metafóricos, mas também porque nos permitiu vislumbrar a possibilidade de construção de uma espécie de laço: cinema e família, ambos fenômenos socioculturais ${ }^{1}$, poderiam ser

1. Em Linguagem e cinema Christian Metz, ao tratar do fato fílmico dentro do cinema, salienta que aquilo "o que globalmente denominamos 'o cinema' (e num grau menoro que denominamos 'o filme') se nos oferece, na verdade, como um vasto fenômeno sócio-cultural, uma espécie de fato social total no sentido de Marcel Mauss, compreendendo, como sabemos, importantes aspectos econômicos e financeiros"; faz ainda uma ponderação - a qual nos é muito interessante - relativa ao fato de que, tendo o 
interligados não apenas pela problematização temática (a família como tema, assunto, argumento desenvolvido no cinema), ou seja, pela vertente do plano do conteúdo, mas até mesmo pela via da associação formal, pela vertente do plano da expressão. Pelo menos, algum tipo de cinema e algum tipo de família, acreditamos, poderiam ser, nesse âmbito, mais estreitamente correlacionados.

Cinema e tela, família e casa. A família no cinema, a casa na tela. Molduras. Luz e escuridão, na família e no cinema.

Difícil explicitar a idéia desse encontro. Mas é um caminho, e que se nos insinua como filão para estudos futuros - dependentes, obviamente, de incursões pelas esferas do cinema e pela problemática da família. Um caminho que, mesmo enquanto nos ativemos apenas à intenção do estudo presente, nos deu o que pensar, principalmente quando ousamos divagar, lançando mão de breves e provocativas analogias. O cinema espanhol, entretanto, parece autorizar esse laço que nos aventuramos a propor: é pródigo em películas que representam a família. Essa prodigalidade é fato, e fato facilmente comprovável. A ponto de se poder falar em uma poética da família, nos termos em que define Eduardo Peñuela Cañizal em seu ensaio intitulado "A corrosão do relato falocêntrico":

(...) a deterioração das relações sociais e os ditames da censura foram, embora possa parecer paradoxal, os motivos que levaram os principais cineastas espanhóis à construção de uma poética da família. Isto é, no seu afã de atinar com os instrumentos de representação convenientes à expressão dos aspectos mais primordiais da urdidura de sigilos, os cineastas, penso, encontraram na poética, entendida como uma disciplina que tem por objetivo o conhecimento exaustivo dos princípios gerais da poesia (GROUPE , 1970:25), as ferramentas apropriadas. (Peñuela Cañizal, 1996, p.21)

Prosseguindo, o autor discorre sobre texto fílmico e família, explicitando os termos de seu entendimento - no qual estaremos

cinema entrado para os costumes, se faz necessário começar a compreendê-lo em seus diferentes aspectos, e para tanto fazer alguma idéia dos diferentes pontos de vista sob os quais o seu estudo pode ser abordado. (Metz, 1980, p. 7-9) 
ancorados, neste trabalho - a respeito da expressão poética $d a$ família:

(...) a poética se ocupa das metáboles em que se engendra a poesia, sejam elas metáforas, metonímias, sinédoques, alegorias, eufemismos, elipses, assíndetos ou, simplesmente, sinéreses. (...) a família, enquanto agrupamento de pessoas formado a partir das regras de um código ou de vários códigos, se apresenta também como um texto social sujeito, como qualquer texto, a todo tipo de mudanças, alterações ou rupturas. (...) Expostos de maneira simplista os conceitos de poética e de família, o que desejo dizer com a expressão poética da família é que o cinema, neste caso o espanhol, se serve dos princípios da poesia para expressar os desvios que ocorrem, com mais ou menos evidência, cada vez que, no seio da família, as regras que a legitimam moral, religiosa, jurídica e socialmente são desrespeitadas. (Peñuela Cañizal, 1996, p. 21-2)

Os filmes que se inserem na tendência do quadro esboçado estruturam-se a partir de um jogo de tensões significativas sobredeterminado pelos engastes dos processos metonímicos nas formas conteudistic as mais profundas da metáfora. A metáfora, nesse caso, assume um indiscutível protagonismo retórico; comprovado pelo engastamento da transparência metonímica nos conteúdos dos processos metafóricos no momento em que tais filmes se aprofundam nas penumbras dos mais encobertos relacionamentos familiares (Peñuela Cañizal, 1996, p.22-3).

Talvez não por acaso, então, o cinema espanhol (ou, ao menos, o cinema espanhol inspirado em Luis Buñuel), em diversos de seus momentos configura-se, como pode ser observado no que se apresenta nos supostos primeiro ou segundo planos de seus filmes, como representativo e ilustrativo de temáticas de ordem política e familiar $^{2}$. A censura imposta pelo franquismo, sabedora da ameaça

2. Essa característica, que se intensifica em alguns filmes específicos como, entre outros, Las hurdes (1932), Los olvidados (1950), Viridiana (1961), é notável em praticamente todo o universo da obra de Buñuel. 
que a abordagem de assuntos proibidos representa para a estabilidade das instituições autoritárias, com o conseqüente desvelar de possíveis fragilidades, segredos ou barbaridades, restringiu a realização artística - o que acabou por incitar alguns artistas a buscar recursos, os mais sutis, para expressar e veicular o que não era permitido.

O cinema trabalha com sucessões de enquadramentos. dispondo de recursos como travellings, usos peculiares de lentes específicas, cortes que separam um plano de outro plano, hierarquizações, montagens. O olho enquadra, a câmera enquadra. As formas mais ou menos estereotipadas de enquadramentos podem se constituir, mesmo, num estilo de captação de imagem: uma determinada aproximação ou um certo distanciamento que são mantidos em relação ao objeto, um certo uso, específico e característico, que o artista (ou sujeito da enunciação fílmica) faz do enquadramento. Em termos bem gerais, os enquadramentos selecionam, dentre uma diversidade dada, aquilo que pretendem realçar, tornar significativo ou pertinente.

Enquadrar, assim, não deixa de ser também uma forma de promover e de realizar construções: tanto pela aproximação quanto pelo distanciamento do objeto - ou do sujeito - em tela, o enquadramento institui parâmetros; estabelece, por meio do realce ou do apagamento, marcações de diferenças e de similaridades. A família, por sua vez, ao tecer seu tecido, enquadra. Em termos metafóricos, evidentemente, mas enquadra. Monta, prepara, arma telas e enquadra: enquadra na casa, no casamento, no descasamento; na linhagem, na descendência, na hierarquia. No álbum. Ou fora do álbum, no espaço heterotópico, por exclusão.

Quando o cinema enquadra e emoldura a instituição familiar, fazendo dela um tema - como no caso reiterativo do cinema espanhol -, parece-nos que já nisso poderíamos ver, em princípio, uma subversão. E uma subversão de caráter bastante original, na medida em que, a princípio, para realizá-la, o cinema simplesmente faz aquilo que sempre fez: enquadra. Chama a atenção, portanto, sem chamar a atenção: como sempre enquadrou tudo, enquadra também na tela uma instituição que, de resto, desde sempre esteve familiarizada com enquadramentos. Enquadramento dentro de 
enquadramento, encaixes. Enquadrada, entretanto, a família revelase. E revela. Da sombra, no escuro, a luz. Alarme. Como em A casa de Bernarda Alba.

Para estudar a trajetória do cinema espanhol em suas representações da família, iniciamos um percurso por vários filmes, com a intenção de demarcar pontos para aprofundamentos futuros. Ainda estamos trilhando, desenvolvendo esse percurso. Por ora, e como ponto de partida para primeiros ensaios analíticos, concentramo-nos em aspectos relativos à análise de duas películas: Cría cuervos (1975), de Carlos Saura, e Todo sobre mi madre (1999), de Pedro Almodóvar.

Como se sabe, ambos os diretores das películas que nos propusemos enfocar foram influenciados ${ }^{3}$ pelo cinema de Luis Buñuel, o qual não apenas tratou enfaticamente de questões afetas ao universo da instituição familiar como construiu uma obra marcadamente comprometida, a nosso ver, com a crítica e com a utopia da subversão e ruptura de qualquer sistema pré-estabelecido. Abordamos o estudo do cinema espanhol em alguns recortes de suas representações da família:

Nas leituras de Cría cuervos e de Todo sobre mi madre, dentre os aspectos fílmicos e cinematográficos de cada filme, no sentido em que Christian Metz (1980, p.23-56) empresta aos termos ${ }^{4}$, foi nossa intenção explorar mais enfaticamente os fílmicos - o que não

3. Não é nosso objetivo aprofundar esse assunto, o qual exigiria o desenvolvimento de estudos - específicos e detalhadamente comparativos - da filmografia de Buñuel, de Saura e de Almodóvar. Cumpre mencioná-lo, todavia, a título de referência e registro, uma vez que, tanto no plano da expressão quanto no do conteúdo, ecos de Buñuel (explorações, de maneira inusitada, de questões relativas ao âmbito da política, família e religião, aos relacionamentos humanos, à tirania e opressão, a tentativas de aproximação das pulsões libidinais, a desăfios e quebras de padrōes e preconceitos, etc.) são audíveis no universo da obra dos outros dois cineastas, conforme se pode comprovar, muitas vezes por meio de intertextualidades marcadamente explicitadas, em diversas películas - tais como, apenas para citar alguns dentre os muitos exemplos possíveis, La caza (1965), La prima Angélica (1973), Cria cuervos (1975), Elisa, vida mía (1976), todas de Saura; no que se refere a Almodóvar temos, também entre outros, Pepi, Luci, Bom y otras chicas del Montón (1980), Matador (1986), Carne trémula (1997), Todo sobre mi madre (1999).

4. Metz aponta duas possibilidades distintas de caminhos para se estudar os filmes: um caminho determinado pelo estudo das linguagens cinematográficas em geral, e outro marcado pela ênfase nos aspectos fílmicos específicos de cada filme. 
quer dizer, evidentemente, que não reconheçamos a relevância dos aspectos cinematográficos de ambos. Com base no entendimento de que na dialética da cultura um texto se abre às possibilidades de se relacionar com outros textos e, dessa maneira, entra nos domínios do simbólico ou, para usar outro termo, da linguagem (Peñuela Cañizal, 1996, p.16), tratamos como textos os referidos filmes, assim como o fizemos com a família,ou seja: enfocamos textos fílmicos representando textos familiares.

\section{Dos filmes: junções e disjunções}

Cría cuervos e Todo sobre mi madre. Dois enquadramentos, duas famílias, dois filmes. Um engendrado no seio da ditadura, outro gestado na praça da democracia. Dois textos fílmicos completamente distintos? Sim e não. Desiguais as bases, distintos os tempos. Diversas as figuras e as figurações. Tudo, porém, na mesma Madrid, tudo estampado na mesma terra-argila. Múltiplas texturas familiares - estranhas texturas, às vezes -, mas sempre textura. Sempre enquadramento, porque sempre a representação cinematográfica do texto de uma, digamos assim, família. Rocas e fios, luzes e telas. Junções e disjunções.

Nas telas de Cría cuervos e de Todo sobre mi madre, vemos no primeiro filme a casa, imagem fortemente destacada. Casa com piscina no quintal. Dentro da casa, uma menina triste, grandes olhos contemplativos. A piscina não tem água e o quintal tem muros. Altos muros. Na casa, a menina (Ana) tem uma gaiola e uma geladeira. $\mathrm{Na}$ geladeira, um prato, com restos de bicho morto; na gaiola, um resto de bicho vivo ${ }^{5}$. Todo sobre mi madre tem trilho e tem trem, tem praça e terreno baldio. Casa própria - fixa, enraizada e bem delineada,

5. A protagonista de Cría cuervos, em várias ocasiões em que é enquadrada sozinha, é associada a pés de aves depositados num prato e conservados na geladeira, e a um pequeno bicho de estimação que mantém em uma gaiola - provavelmente devido ao estado de imobilidade e clausura em que se encontram tanto a menina quanto os restos mortais de aves e o animal engaiolado. Morrendo, o animal é colocado numa caixa (branca como a geladeira que abriga os restos de aves) e enterrado, durante breve ritual organizado pelas crianças; na ocasião, Ana lambuza-se de terra, lembrando um devaneio da protagonista de Belle de jour (1966) de Luis Buñuel. 
não tem. Apenas abrigos provisórios, temporários, alugados. Tem cidade, teatro, e cemitério. Teve um menino que desejava ser escritor e uma mulher que acabou contando a história que deveria ter por ele sido escrita. Televisão e hospital ${ }^{6}$, também tem. E um bebê. Na praça, um cachorro ${ }^{7}$; tomando conta de um homem. O homem, enjaulado na loucura mansa.

Não tem mãe, na casa de Cría cuervos, e pai também não tem. Mas teve, e teve os dois: uma mãe quase pianista, um pai completamente fardado. Na foto, o casal: ela, um sorriso; ele, medalhas e um cavalo. Surpresa pouca e perguntas muitas. O pai teve um revólver e a mãe uma doença. Nenhum sobreviveu.

Todo sobre mi madre não teve casa, mas tem mãe (Manuela) andando para lá e para cá ${ }^{8}$. Solta no mundo. Sozinha, ela mais o filho (Esteban). Enfermeira, atriz, cozinheira. O pai? Um nome (Esteban, como o filho) e um lugar. Pessoalmente, ausência e segredo. E surpresa, também: tinha sido um pai com tetas. Da foto foi eliminado ${ }^{9}$. Perguntas muitas. O filho morreu, mas só por algum

6. A televisão, se não chega a ser uma metáfora reiterada nesta película, ainda assim tem presença significativa na narrativa: é, de certa forma, um elo, um canal que desloca para o lado de dentro do espaço doméstico aquilo que está fora - levando, também, para fora o que está dentro. A televisão (e, por extensão, o vídeo) torna familiar o estranho, e funciona como uma janela (ainda que falsa) para o exterior. Já a imagem do hospital, relativamente descolado de sua função habitual (caracterizada pelo predomínio do sofrimento), é recorrente no cinema de Almodóvar: constituise num espaço onde se misturam atividades médicas e lúdicas, e onde as pessoas interagem - numa movimentação atrelada a noções de vida e transformação.

7. Em oposição ao elemento bicho de Cría cuervos, o cachorro do filme de Almodóvar é um animal que vive em relativa liberdade, movimentando-se entre a casa paterna de Rosa e a rua; apesar de estar sendo usado a serviço do homem, subverte a habitual relação homem/animal doméstico, na medida em que é uma espécie de babá para o pai senil; a mãe, ao levá-lo pela corrente, parece ter dificuldade para contê-lo - sendo forçada a segui-lo.

8. É a mãe que vai e que vem. É por eu ser um serzinho já tomado pelo simbólico, e por haver aprendido a simbolizar, que podem dizer que ela vai e que ela vem. Em outras palavras, eu a sinto ou não sinto, o mundo varia com sua chegada e pode desaparecer. A pergunta é: qual é o significado? O que quer essa mulher aí? Eu bem que gostaria que fosse a mim que ela quer, mas está muito claro que não é só a mim que ela quer. Há outra coisa que mexe com ela - é ox, o significado. $E$ o significado das idas e vindas da mãe é o falo. (Lacan, 1999, p. 180-81)

9. A fotografia, elemento presente desde a abertura do filme de Saura, também se faz presente na película de Almodóvar. No primeiro caso, as fotos exibidas tendem a 
tempo: dos confins do útero, a mãe trouxe-o de volta. Vingou o bebê. O pai, doente de AIDS, sucumbe.

A mãe não morre, como no filme de Saura, mostra Todo sobre mi madre; e o bebê vai vivendo. Ambos em movimento, transitando pelos caminhos da cidade e pelas estradas que conduzem a outras cidades. A imagem da cidade, exaustivamente reiterada, permeia toda a narrativa fílmica de Almodóvar contrapondo-se à imagem da casa que domina a cena da película de Saura. Cría cuervos, por seu lado, acaba mostrando que a menina triste saiu da casa e virou mulher. Mãe e pai, mortos ambos.

Em A conquista do presente Michel Maffesoli (2001) fala a respeito do papel que desempenham os espaços físicos como produtores dos hábitos e costumes cotidianos que, por sua vez, possibilitam a estruturação comunitária; ao discorrer sobre a "encarnação" da socialidade que necessita de um solo para se enraizar, o pesquisador aproxima a cidade da casa e discorre sobre seus elementos de junção, disjunção e ambigüidades, lembrando que se a casa da infância é o paradigma de toda raiz ou busca de raízes, de estabilidade, o espaço local é, por sua vez, o fundador do estar-junto de toda comunidade:

(...) A cidade ou a casa, como sedimentação das histórias passadas, do tempo decorrido, servem então de pólos atrativos, eles são fortalezas sólidas nessa luta permanente que é o afrontamento do destino. É aí que convém buscar o fundamento do apego afetivo ou passional que liga o indivíduo ou o grupo a qualquer que seja o território. (...) A cidade de todos os dias, aquela onde se enraízam nossos afetos, vivese na imperfeição, mesmo e sobretudo quando ela evoca, imaginariamente, uma figura mítica em que se realiza a harmonia plural. A espacialidade onde 'tudo junto forma

enfatizar o caráter de morte, inerente à fotografia, na concepção de Roland Barthes (1984); no segundo, a ênfase recai sobre os restos que, do registro, conseguem, de alguma forma, remeter e incitar à noção de vida. Recorrente e significativa no universo das duas películas, a imagem da fotografia parece estar, desde o seu surgimento, estreitamente associada à instituição familiar: são notórios o apreço e o apego que, em geral, nutrem as familias por seus álbuns de fotografias. 
um corpo' é um lugar dinâmico feito de ódios e de amores, de conflitos e de distensões, é uma 'casa' objetiva e subjetiva onde, na monotonia ou na agitação, vive-se uma socialidade cotidiana que, como toda situação mundana, é fundada no limite. (...) a trama social tem a fisionomia das ruas que a compõem. Existem códigos, rumores, intrigas, ódios e solidariedades que se exprimem nas situações e hábitos particulares de uma cidade, de um vilarejo, de um bairro. (Maffesoli, 2001, p.81, 86-7 e 93)

Fora de casa, a mulher de Cría cuervos (Ana quando adulta) no analista. Muitas perguntas, ainda. Mas, no filme, a dona da história. Uma tela toda para ela. Solitária, enquadrada no centro da tela branca, Ana fala e questiona. $\mathrm{O}$ bebê de Todo sobre mi madre, no colo da mãe. Há tela no futuro para um filme todo sobre ele? Muitas perguntas. De claro, a transformação nos papéis familiares.

Os filhos - Ana e Esteban - querem falar, querem contar, querem saber. E falam, e contam, e são contados. Falando (e quase não conseguimos escapar à tentação de tratar da coincidência que, na língua portuguesa, aproxima a palavra fala da palavra falo), se constituem como sujeito. Ao final de ambos os filmes, o pai, derrotado, é preservado no simbólico. Sua palavra - seu nome ${ }^{10}$ - permanece. Os filhos, então, sugerem os desfechos, têm a possibilidade de conseguir assimilar o passado, o já vivido e efetivamente deixar a casa rumo à construção de sua própria história ${ }^{11}$. Pode-se dizer que

10. (...) o pai é uma metáfora. (...) é um significante que surge no lugar de outro significante. Digo que isso é o pai no complexo de Édipo, ainda que isso venha a aturdir os ouvidos de alguns. (Lacan, 1999, p.180)

11. No princípio, portanto, era o Pai, o Falo e o Verbo: é em torno dessa trilogia que Lacan constrói o Édipo como um invariante inelutável inscrito no inconsciente. Este é 'estruturado como uma linguagem', mas não como a língua, pois a cadeia simbólica é regida aqui por um 'significante mestre', o falo, ao mesmo tempo signo e objeto do desejo. Não há significante do sexo feminino; o falo é pois a 'unidade-sexo' que ordena, em tomo da castração simbólica, a diferença dos sexos e das geraçôes. É ele que sustenta a função paterna: pois 'o Édipo é consubstancial ao inconsciente' como lugar do pacto, do Outro como pai morto tornado metáfora ou nome, e de sua palavra interditora e salvadora. Essa é a determinação simbólica do sujeito, que transcende toda determinação bioanatômica: essa reinterpretação de Freud torna a lei mais radicalmente 
o presente, nas narrativas fílmicas, reconstruiu-se (passando a limpo o passado, colocando-o em dia) em prol da construção do futuro - que está fora do enquadramento e ao qual não temos acesso, enquanto espectadores, mas que se configura como uma promessa.

Nos dois tecidos fílmicos, entranha-se o segredo. E em ambos se infiltra o desejo, desejo de saber. Os personagens esforçamse por desfiar o segredo, desembaraçá-lo da trama em que se esconde e por promover uma espécie de desatamento de nós. No filme de Almodóvar, há desejo, muito desejo - difuso, desconexo, espalhado em muitas direções, distribuído de forma diversa e desigual por entre os personagens -, mas fortemente presente. Presença que contribui para com a movimentação que desenrola a trama e desvela o encoberto, ao menos em parte. Na casa de Ana, o que predomina é o dever - quase não se percebe espaço para o desejo, embora se goze. É como se do útero, ali sugerido pela presença da mãe nas lembranças de Ana, somente houvesse o buraco, viscoso; nada de novo, nada do ovo: só a clausura (aconchegante) da concha escura. Mas o desejo é transformador. Assim, ainda que se verifique na narrativa uma tendência de organização textual amarrada, encurraladora e claustrofóbica, na qual predomina a contenção, o compactado, tal tendência é razoavelmente afrouxada à medida que o filme vai se aproximando do final - até que a protagonista e suas irmãs transpõem os muros e saem da casa. Trajando uniformes e em direção à escola, é fato. Mas fora de casa, fora do claustro.

As ambigüidades e contradições que se verificam no universo dos dois filmes são, em nosso entendimento, a representação artística, simbólica dos nós e padronagens que caracterizam o texto familiar tradicional - usualmente marcado por simultaneidades e oposições de sentimentos e de situações diversas, do tipo inclusão/exclusão, abertura/clausura, atração/repulsa, conforto/desconforto, amor/ódio. Um texto no qual lugares e papéis pré-fixados acabam por assujeitar, dentre os componentes

proscritiva. Mas de que nos salva ela? Do gozo e do horror dos tempos primitivos da espécie como do individuo. Do real, diz Lacan. (Kaufmann, 1996, p. 142) 
da família, tanto aqueles que ocupam posições de mando (seja em caráter permanente ou circunstancial) quanto os que obedecem. Instala-se, então, tendencialmente, uma relação de escravidão, assentada num ambiente claustrofóbico e viciado, com escassas possibilidades de arejamento. Escassas, mas não inexistentes. As oportunidades de transgressão se viabilizam, paradoxalmente, pelas brechas e fendas que se alojam no esconderijo das falhas verificáveis no próprio tecido da família.

Os dois filmes apresentam textos que acabam por revelar e problematizar, diríamos, as marcas de engessamento e de claustro que caracterizam o texto familiar. O cerne da questão, parece-nos, estaria nos lugares da mãe, do pai e dos filhos tal como se verifica na família nuclear freudiana - e nas conseqüências passíveis de se verificar quando tais lugares (principalmente o do pai e o da mãe) se tornam o que chamamos de hipertrofiados.

Um pai tirano e autoritário pode exercer, sobre os filhos, efeitos tão paralisantes ou nefastos quanto uma mãe que assim o seja. Em Cría cuervos Saura mostra a família submetida à ditadura do pai; Almodóvar, no filme Matador (1985), explora os efeitos deletérios provocados no filho pela tirania e pelo autoritarismo da mãe. Assujeitados e submetidos a um poder que encarcera e imobiliza, os filhos tendem a eternizar os comportamentos e os procedimentos de repressão, repetindo-os acriticamente; e a família, então, não tem efetivas possibilidades de crescimento e de desenvolvimento - fica presa no próprio texto, em todos os sentidos. Esgota-se nela mesma.

Em Cría cuervos e em Todo sobre mi madre, todavia, estes lugares acabam por não se mostrar, de modo algum, hipertrofiados. No primeiro, a figura que ocupa o lugar do pai é defunta, está fragilizada e sem forças: é uma imagem de morte, de algo que está se acabando. No segundo, a figura da mãe, mesmo sendo marcante e reiterada, não é a figura da mãe convencional; a personagem, sempre em construção, mostra-se aberta e cambiante, toda ela movimento e multiplicidade: apresenta-se como uma promessa de vida, de novas imagens. 


\section{Do cinema: família e subversão}

Considerando o que foi exposto até aqui, dentre as diversas questões que se configuram, uma se nos afigura particularmente intrigante: com que lentes olhar, e de que ângulo, para as configurações familiares que se parecem delinear a partir de Cría cuervos e de Todo sobre mi madre? São filmes que nos permitem estabelecer uma polarização no mínimo interessante: a película de Saura apresenta a família - ou o que restou da família - na Espanha da ditadura; a de Almodóvar, retrata um espectro de família na Espanha em tempos de consolidação democrática.

Em Cría cuervos, Saura reitera as metáforas de encierro já presentes em outros de seus filmes; referindo-se a $L a$ caza, Peñuela Cañizal discorre sobre essa figura e seus efeitos de sentido:

(...) metáforas em que se manifestam os conteúdos mais tensos do conflito sobredeterminado pela negação do espaço da cidadania e a conseqüente afirmação de um espaço interior onde a intimidade das personagens é vivida, por assim dizer, em abismo. (...) Às vezes, as pretensas escabrosidades dos segredos familiares aparecem diluídas na representação de uma asfixiante atmosfera social para a qual confluem tanto as aspirações vindas da redução dos espaços da cidadania quanto às irradiações de traumas abafados nos enclausuramentos da família. (..) Em outras oportunidades, a redução do espaço da cidadania se faz tênue referência e, com isso, os traços mais recônditos dos relacionamentos afetivos assumem, nos palcos da expressão metafórica, uma insinuante proeminência. (Peñuela Cañizal, 1996, p.25)

Todo sobre mi madre, por seu lado, com suas inversões e deslocamentos, engendra metáforas de alargamento e abertura, além de provocar desordens que afetam o plano da expressão $e$ abalam a tranqüilidade semântica com que, em nome de uma moral arbitrária, a família acoberta muitas das suas pretensas escabrosidades (Peñuela Cañizal, 1996, p.26). Essas rupturas com 
o padrão estabelecido têm sido trabalhadas por Almodóvar em diversos de seus filmes, nas mais variadas abordagens temáticas; naqueles que focam a família, a marca da carnavalização nos processos de representação parece dizer que, por mais que seja reiterado através dos séculos, é vão o esforço que se tem envidado para aprisionar instintos e pulsões libidinais nos meandros da instituição familiar. Na trajetória tumultuada e plural de Manuela, a protagonista, bem como na de outros personagens da trama, o desejo, com sua força subversiva, estabelece uma espécie de jogo de desmascaramentos e funciona como propulsor de mudanças.

É possível constatar que o texto familiar representado no filme de Saura, impregnado pelo espectro da figura paterna e assentado no tempo em que a Espanha vive os estertores da ditadura, está comprometido com as tensões da tragédia edipiana, de que nos fala Sigmund Freud (1999) em Totem e tabu. Já na narrativa da película de Almodóvar, a qual se desenrola no período da consolidação do regime democrático, tal não acontece: uma vez que o que se verifica ali não é propriamente a existência de um agrupamento familiar tradicional (ao menos não no sentido convencional do que se entende pela noção de família nuclear freudiana), não há espaço para os emaranhamentos característicos do mito de Édipo. Assim, se diluem ou mesmo se desfazem, sem conflitos trágicos, os nós de arbitrariedade estabelecidos pelo conjunto de significantes - pai, mãe, filhos, irmãos, tios, sobrinhos, primos - que determinam as relações de laços e lugares ${ }^{12}$.

O lugar do pai, na filmografia de Almodóvar, tende a não ter destaque ou mesmo a desaparecer; em oposição à figura paterna esboçada de forma tênue e esmaecida, prevalece figura da mãe, que ocupa, esta sim, lugar actancial determinante, de onde tece e articula transformações e subversões, junções e disjunções; na narrativa fílmica de Todo sobre mi madre, com o impulso original provocado pela movimentação que emana da mãe, tanto ela como os demais personagens se transformam em sujeitos inventivos que, detentores de um poder-fazer revolucionário e libertário, deslocam-se pelo filme

12.Esse argumento é bem próximo do desenvolvido por Peñuela Cañizal (1996, p. 34). 
realizando operações que permitem a inclusão/exclusão de outros textos ao texto que atualizam.

Também se afiguram relevantes, pelo que podem significar em termos de aprisionamento e liberdade pessoal, as questões relativas à esfera da comunicação entre os sujeitos no interior dos agrupamentos familiares - evocadas pela atmosfera pesada, de isolamento e incomunicabilidade que em Cría cuervos configura a solidão de Ana. Para incursões por essas veredas, seria conveniente buscar desenvolver aspectos relativos ao conceito de representação, particularmente aqueles que dizem respeito ao caráter - trágico, ao nosso ver - de imprecisão e imperfeição dos processos de representação e comunicação, o que condenaria o homem ao silêncio e à clausura.

Todavia, perambulando um pouco nesse âmbito, em princípio nada impede que aquilo o que nos pareceu ser condenação possa ser também percebido como alforria, uma vez que as falhas nos processos comunicacionais criam brechas - e, por meio de tais brechas, instauradas a partir do que não é integralmente dito ou simplesmente não-dito, o homem pode ser salvo do "horror do real". Há uma dimensão insondável contida na gênese de toda relação comunicacional, principalmente no que se refere ao campo da palavra:

Uma palavra não é palavra a não ser na medida exata em que alguém acredita nela. (...) É nessa dimensão que uma palavra se situa antes de tudo. A palavra é essencialmente o meio de ser reconhecido. Ela está aí antes de qualquer coisa que haja atrás. E por isso, é ambivalente e absolutamente insondável. O que ela diz, será que é verdade? Será que não é verdade? É uma miragem. (Lacan, 1986, p.272-73)

As análises fílmicas empreendidas demonstram que os textos familiares tradicionais tendem a aprisionar e a imobilizar o sujeito criador - impondo-lhe padrões, lugares e papéis que lhe restringem a ação, limitam o desenvolvimento e atrofiam o gesto transformador, cerceando-lhe a manifestação espontânea do desejo. 
Analisando os esquemas narrativos representados nos textos fílmicos selecionados, tivemos a oportunidade de verificar que as relações de comunicação ali, quando existem, configuram-se marcadamente problemáticas.

As duas películas incitam à reflexão sobre a eviidência de que se, por um lado, os modelos familiares vigentes - nos filmes e fora deles - já há muito vêm dando sinais de deterioração e/ou esgotamento, por outro é igualmente inegável que uma intenção de constituir uma espécie de família continua a ser explicitada na coreografia que movimenta o cotidiano dos personagens envolvidos na trama narrativa - e também, parece-nos, na que move a rotina de considerável parte dos expectadores que se encontram no espaço heterotópico.

Na medida em que Cría cuervos e Todo sobre mi madre situam-se como textos fílmicos que abrem o interdito e desmontam o já dito, ambos - cada qual com suas lentes peculiares - se orientam na perspectiva sedutora, ao nosso ver, da abertura e da libertação:

Tricotar, sim, mas sem ter o movimento das mãos preso às normas de um padrão predeterminado (...) Tecer, por conseguinte, malhas cuja textura não sirva, simplesmente, para ocultar o corpo e as metáforas de que a sua nudez se reveste, como em la maja de Goya nos arqueados canapés da cultura. (Peñuela Cañizal, 1996, p.29)

É instigante tentar vislumbrar para quais perspectivas familiares apontam os filmes estudados - depois do esgotamento do modelo autoritário evidenciado por Saura e de transposto o período de transição e consolidação da prática de procedimentos de inovação libertária ensaiados no texto fílmico de Almodóvar - e descobrịr como pensar essa família e esses textos familiares nascentes com os significantes ora disponíveis.

O filme de Almodóvar parece oferecer uma alternativa de escape em relação ao esquema da família convencional e tradicional - mas, com essa alternativa, desarticula a idéia de família. A palavra 
da mãe, em Todo sobre mi madre, não mais constrói o pai - tudo está fundado e calcado sobre a mãe, embora a figura dessa mãe não aparente ser hipertrofiada. $\mathrm{O}$ que se tem, no entanto, é uma família de certa forma manca, quebrada: o filho fica se perguntando sobre esse pai ausente, e morre; parece refazer-se, em seguida, na figura do bebê - mas o bebê é ainda uma promessa, e seu futuro não é mostrado no filme.

Talvez, a saída esteja na perspectiva daquilo que de revolucionário está contido na fala de Agrado, a multifacetada e diegeticamente auto-construída personagem de Todo sobre mi madre: Custa muito ser autêntica, senhora. E nessas coisas não se pode economizar... Porque se é mais autêntica quanto mais se parece com o que se sonhou para si mesma ${ }^{13}$. A autenticidade e a liberdade para compor o próprio corpo, de que fala Agrado, não deixa de ser, ao nosso ver, análoga à utopia libertária presente no desejo de compor o próprio texto. Enquadramentos efêmeros, tudo construção, tudo provisório. Movimento.

13. Trecho da legenda da fita VHS do filme Tudo sobre minha mãe, cópia brasileira do filme Todo sobre mi madre, de Pedro Almodóvar. 


\section{Bibliografia}

BARTHES, Roland. 1984. A câmara clara - nota sobre a fotografia. Rio de Janeiro: Nova Fronteira.

FLOCH, Jean-Marie. 2001. "Alguns conceitos fundamentais em semiótica geral". In: Documentos de estudo do Centro de Pesquisas Sociossemióticas, 1. São Paulo: Edições CPS.

FREUD, Sigmund. 1999. Totem e tabu. Rio de Janeiro: Imago.

FREUD, Sigmund. 1981. Obras completas. Madrid: Biblioteca Nueva.

GREIMAS, Algirdas Julian \& COURTÉS, Joseph. 1979. Dicionário de semiótica. São Paulo: Cultrix.

GROUPE, $\mu$. 1990. Traité du signe visuel. Paris; Seuil.

KAUFMANN, Pierre. (ed.) 1996. Dicionário enciclopédico de psicanálise - o legado de Freud e Lacan. Rio de Janeiro: Jorge Zahar.

LACAN, Jacques. 1987. Os complexos familiares. Rio de Janeiro: Jorge Zahar.

LACAN, Jacques. 1999. As formações do inconsciente. In: $O$ seminário, Livro V. Rio de Janeiro; Jorge Zahar.

MAFFESOLI, Michel. 2001. A conquista do presente. Natal: Argos.

METZ, Christian. 1977. A significação no cinema. São Paulo: Perspectiva.

METZ, Christian. 1980. Linguagem e cinema. São Paulo: Perspectiva.

PEÑUELA CAÑIZAL, Eduardo. (org.) 1993. Um jato na contramão - Buñuel no México. São Paulo: Perspectiva / Com-Arte / ECA.

PEÑUELA CAÑIZAL, Eduardo. (org.) 1996. Urdidura de sigilos ensaios sobre o cinema de Almodóvar. São Paulo: Annablume / ECA / USP.

SAURA,Carlos. 1975. Cría cuervos... Madrid: Querejeta Ediciones.

SLUZKI, Carlos. (org.) 1971. Interacion familiar. Buenos Aires: Tiempo Contemporâneo.

STONE, Rob. 2002. Spanish cinema. London: Longman / Pearson Education. 